\title{
O FLUXO FORMULATIVO DO TEXTO FALADO DOS VLOGS: DESCONTINUIDADE E FRAGMENTAÇÃO
}

\author{
Anderson Rangel Freitas de Aquino \\ Mestre em Letras: Linguagens e Representações \\ pela Universidade Estadual de Santa Cruz (UESC) \\ anderson.letras@hotmail.com \\ Maria D'Ajuda Alomba Ribeiro \\ Professora Emérita da Universidade Estadual de Santa Cruz (UESC). Professora \\ PVNS/CAPES/da Universidade Federal de Roraima (UFRR). \\ profdajuda@gmail.com
}

\section{RESUMO}

Os vlogs são produções textuais híbridas que se materializam sobretudo através da modalidade falada da língua. Nesse sentido, é necessário que os textos atendam não apenas às contingências do momento de sua elaboração, mas também às demandas do YouTube. Por conta disso, as falas não são totalmente espontâneas, mas costumam passar por um processo de edição que evidencia como o texto falado pode desenrolar-se de modo descontínuo. Assim, objetivamos refletir acerca do modo de construção textual dos vlogs, sobretudo quanto ao fluxo formulativo. Para tanto, utilizaremos sobretudo as contribuições de Barros (2000), Marcuschi (2005, 2008), Urbano (1998), Comolli (2007) e Cruz (2010). Para - corpus, selecionamos o canal de Francine Ehlke em virtude do formato dos vídeos e quantidade de inscritos. Evidenciamos que as descontinuidades presentes no texto falado dos vlogs atribuem ao texto maior expressividade e dinamicidade, sendo utilizadas como estratégias para a construção de sentido desse gênero.

Palavras-chave: Vlogs; Texto falado; Edição; Descontinuidade.

\begin{abstract}
Vlogs are hybrid textual productions that materialize mainly through spoken language. In this sense, it is necessary that the texts meet not only the contingencies of the moment of their elaboration, but also the demands of YouTube. Because of this, the speeches are not entirely spontaneous, usually going through an editing process that shows how the spoken text can unfold discontinuously. Thus, we aim at reflecting on the textual construction of vlogs, especially regarding the formulative flow. Therefore, we will mainly work with the contributions of Barros (2000), Marcuschi (2005, 2008), Urbano (1998), Comolli (2007) and Cruz (2010). For the corpus, we have selected Francine Ehlke's channel because the format of the videos and the number of subscribers. We demonstrate here that the discontinuities present in the spoken text of the vlogs add to the text a stronger power of expression and dynamism. Such discontinuities are then used as strategies for the construction of meaning in this genre.
\end{abstract}

Keywords: Vlogs, Spoken text, Editing, Discontinuity. 


\section{INTRODUÇÃO}

A produção textual contemporânea tem se tornado mais dinâmica e visual, o que impacta na organização dos textos e na sua produção de sentidos. O gênero vlog, por exemplo, destaca-se pela forma criativa de produzir conteúdo, visto que possui estrutura multimodal, cuja narrativa audiovisual se realiza utilizando técnicas de enquadramentos, ângulos e edições conforme os objetivos do produtor.

Assim sendo, o caráter híbrido e multimodal dos vlogs favorece a utilização de diversos recursos que ampliam a forma de produzir textos. Os artifícios multimidiáticos são utilizados também para atribuir à fala uma fluência específica, fazendo com que os textos se tornem mais expressivos e originais. O fato de as produções serem feitas em vídeo permite que o fluxo da fala seja descontinuado através de montagens e cortes. De acordo com Comolli (2007), cria-se assim uma estética da abreviação, em que as falas são fragmentadas para promoverem celeridade e dinamicidade aos conteúdos.

Nesse sentido, verifica-se uma fala que não é inteiramente espontânea, mas os vídeos ora apresentam traços típicos da língua falada, ora da língua escrita, como a possibilidade de edição. Partindo daí, objetivamos refletir acerca do modo de construção e apresentação do fluxo formulativo do texto falado dos vlogs. Fundamentados em Marcuschi (2003) e Galembeck (1999), empregamos a metodologia empírico-indutiva, sob uma abordagem qualitativa-interpretativa, pois, devido à natureza interacional e às contigências da fala, estas são as abordagens mais adequadas para o estudo que empreendemos.

Como exemplo de como ocorre a construção textual dos vlogs, utilizaremos um trecho do vídeo "PASSANDO 24 HORAS MAQUIADA! (O Teste mais ARRISCADO)", retirado 
do canal da youtuber Francine Ehlke. Trata-se de material analisado em dissertação de nossa autoria. A escolha do canal deveu-se à grande quantidade de inscritos e aos significativos usos de cortes e efeitos de edição na fala, ressaltando as possibilidades criativas da produção textual.

Na sequência, trazemos alguns conceitos que nos auxiliam a compreender os vlogs. Fazemos também uma discussão acerca da composição multimodal e híbrida desse gênero, destacando as especificidades do texto oral e demonstrando como esses elementos estão imbricados. Por fim, apresentamos algumas reflexões que evidenciam o trabalho dos falantes com a linguagem.

\section{Mas o que são vlogs?}

Os vlogs possuem forma e conteúdo variáveis e de difícil apreensão teórica, de modo que o meio tecnológico, um espaço para experimentações, interfere na sua natureza e organização. Encontramos em Costa (2007) algumas características preliminares acerca dos vlogs. Partiremos dessa concepção:

\footnotetext{
as videografias de si do "Youtube" se caracterizam, em geral, por sua similaridade discursiva e estética. Nesses vídeos, os indivíduos relatam alguma experiência do seu cotidiano, expressam suas opiniões sobre os mais diversos assuntos, apresentam argumentos a favor de sua posição, ou seja, submetem sua vida particular ao julgamento da comunidade. Esse modo de expressão foi consagrado, entre outras coisas, pela própria estrutura do website. Assim, o indivíduo se posta diante da câmera e, por conseguinte, a dota de um olhar, um olhar sem corpo e de pretensa objetividade. (COSTA, 2007, p. 1)
}

Este autor descreve o formato mais tradicional do gênero, embora a tendência seja ao hibridismo e à complexificação. Destacamos então as contribuições de Amaro (2012), quando realiza um estudo e identifica aspectos que os tornam passíveis de 
categorização. Esta divisão envolve tanto o vlog em sua forma mais tradicional, quanto as formas mais atuais e híbridas.

O autor agrupa-os então em (a) autobiográficos: com sua estrutura primitiva, tom confessional; (b) memoriais: usam fatos externos para basear sua opinião; (c) informativos: apresentam notícias ou tutoriais, como é o caso de vlogs de maquiagem; (d) artísticos: os youtubers expõem alguma performance, não só comentando, mas também produzindo alguma forma de arte.

Com vistas a delimitarmos essa variedade, optamos por observar os vídeos que mantivessem uma relação mais próxima com a categoria autobiográfica, que seria, de acordo com o autor, o mais legítimo representante.

Costa (2007) constata que, nesses vídeos, os indivíduos expressam o desejo de serem vistos submetendo sua vida, suas experiências e opiniões à apreciação da sociedade. O resultado é uma complexa relação entre o que é particular e público, real e ficcional, amador ou profissional. Em verdade, subsiste o desejo de que as produções tenham efeito de um material íntimo, verídico e amador, dissimulando o fato de que se trata de um conteúdo midiático elaborado cuidadosamente a fim de ser publicizado.

Desse modo, compreendemos, com Marcuschi, que "não se pode tratar o gênero discursivo independentemente de sua realidade social e de sua relação com as atividades humanas" (2008, p. 155). Assim, todas as estratégias adotadas estão a serviço da indústria do entretenimento, do mercado e do capital. O vlog funciona como um produto rentável, e quanto maior a popularização desses vídeos, maior a possibilidade dos seus produtores se tornarem celebridades.

Sob esse cenário, aqueles que optam por seguir com a carreira de youtubers precisam atender às demandas do YouTube. É necessário que os conteúdos sejam 
adequados ao padrão de consumo da audiência, pois as reações e comportamentos frente a esse material indicarão a influência que esses vlogueiros exercem no meio virtual e fora dele. O próprio ambiente em que os vlogs são publicados reivindicam que sejam ágeis e dinâmicos, favorecendo que os telespectadores mantenham a audiência e evitem distrações.

Interessante notar que os conteúdos não são disponibilizados no YouTube aleatoriamente, mas estão condicionados pelos algoritmos dessa plataforma. De grosso modo, os algoritmos são um conjunto de operações e cálculos através dos quais o YouTube identifica o comportamento e o perfil dos usuários e recomenda vídeos similares aos que costumam assistir. Além disso, os algoritmos são responsáveis por favorecer que alguns produtores de conteúdo sejam mais populares que outros.

O site não divulga informações de todos os critérios nos quais os algoritmos se baseiam para ranquear os vídeos, mas segundo o site Eufórico, alguns deles são: o número de visualizações, a quantidade de comentários e a frequência de postagem. Por mais que o foco seja o conteúdo, ele deixa de ser produzido de modo espontâneo devido a necessidade de se ajustar ao site. Desse modo, quanto maior a quantidade e qualidade dos materiais publicados, maior será a oportunidade de lucro para o usuário e para a própria plataforma.

\section{As contribuições da multimodalidade e da linguagem audiovisual}

Os textos que circulam socialmente cada vez mais são elaborados a partir de diversos recursos semióticos, sobretudo com os avanços tecnológicos. Van Leeuwen (2011) defende que a comunicação é multimodal e que a linguagem verbal não pode ser compreendida sem considerar a comunicação não verbal. É nesse contexto que emerge a 
teoria da multimodalidade, que, de acordo com Carey Jewitt (apud DIONISIO; VASCONCELOS; SOUZA, 2014), trata-se de uma abordagem multidisciplinar que compreende a comunicação e a representação para além dos elementos linguísticos. Assim, são propostos conceitos, métodos e perspectivas de trabalho para a análise de aspectos visuais, auditivos, corporificados e espaciais da interação, bem como da relação entre esses elementos.

Tendo em vista a multidisciplinaridade e o fato de que os vlogs estão cada vez mais sofisticados, utilizando técnicas emprestadas do cinema (enquadramentos, cortes, efeitos) recorremos a algumas noções da linguagem cinematográfica para termos um aparato teórico que considere as técnicas de edição.

Os teóricos consideram que a linguagem cinematográfica foi consolidando-se como tal à proporção em que a câmera deixou de ser estática e passou a apresentar diferentes pontos de vista de uma ação. A partir daí, os filmes passaram a ser produzidos em pedaços diferentes, sendo necessário juntá-los com uma continuidade necessária para que os espectadores conseguissem acompanhar a narrativa (Cf. CRUZ, 2010). O ato de justapor as imagens de um filme é denominado por teóricos como edição.

Cruz (2010) destaca que diversas escolas de cinema experimentaram modos diferentes de unir esses fragmentos. Ela expõe que, numa perspectiva do cinema clássico, como os filmes hollywoodianos, os planos eram montados a fim de dar as narrativas uma fluidez harmoniosa. Assim, através de um princípio de continuidade, buscava-se estabelecer uma sequência fluente de imagens que dissimulasse o fato de que o filme é composto por sequências de unidades menores.

Ferreira (2012) assinala que, neste estilo de edição, permite-se que o espectador siga o enredo com o menor esforço possível e se envolva mais com o conteúdo. Por isso 
são adotados procedimentos para que se aproveite ao máximo a expressividade dos cortes entre os planos, ao tempo em que devem parecer naturais e invisíveis. Este é o estilo mais recorrente nas produções cinematográficas e em outros meios, como na televisão. (CRUZ, 2010)

Outro modo conceitual e estilístico de edição dos filmes desenvolveu-se com o movimento denominado Nouvelle Vogue. Os cineastas dessa corrente defendiam a noção de autor, isto é, buscavam estilo e histórias mais pessoais, rompendo com as convenções estabelecidas pelo cinema hollywoodiano. (DONATO, 2009). Uma das maiores inovações implementadas pela Nouvelle Vogue foi uma técnica de edição chamada de jump-cut.

O jump-cut pode ser definido como um tipo de corte que ocorre através da junção entre duas cenas ou dois planos descontínuos. Ao contrário da edição clássica que buscava a invisibilidade, esse corte manifesta-se de forma mais explícita, com um aspecto mais brusco. É sob esse ponto de vista que Comolli (2007) afirma que

\footnotetext{
a montagem por jump-cut é uma montagem que se mostra. $O$ corte não é mais mascarado [...] ele é marcado como descontinuidade, fragmentação. Ele é renúncia à ilusão de continuidade e de plenitude construída pelo engodo cinematográfico, ele é mesmo a sua denegação. Por mais ínfimo que seja o salto entre dois fragmentos do mesmo plano, ele continua visível. O jump-cut se vê (Quem julga que ele pouco se deixa ver, mente para si mesmo, ou então supõe um espectador desatento, distraído) [...] O corte é revelado em sua nudez. O jump-cut atua, então, como exibição do corte. (COMOLLI, 2007, p. 23)
}

O autor chama atenção para o fato de que este é um recurso marcado pela visibilidade das rupturas. Com a utilização proposital e repetida dos jump-cuts, opta-se por uma estética que chama a atenção dos espectadores para os aspectos técnicos do filme, desviando o foco do enredo para o meio fílmico em si. Assim, é mantida a atenção a partir da fragmentação provocada pelos cortes. 
Em consequência disso, os jump-cuts suprimem da ação os momentos considerados mais fracos, o que faz com que as cenas tenham um ritmo mais acelerado. Estabelece-se, assim, o que Comolli (2007) chama de estética da abreviação, pois, se o telespectador é apressado, é necessário dominá-lo através de uma edição ágil.

Ferreira (2012) afirma que o ritmo rápido é fundamental para capturar a atenção do espectador, pois diferentemente do cinema, em que a atenção está centrada na tela, em outros ambientes é mais provável que se tenha uma infinidade de distrações. No YouTube isso é potencializado, pois os usuários estão diante de uma variedade de links, vídeos relacionados, comentários, o que gera maior possibilidade de dispersão. Desse modo, o jump-cut é uma das estratégias utilizadas para manter o público interessado.

No processo de edição dos vlogs, Assis (2019) afirma que esse tipo de corte objetiva basicamente suprimir os espaços vagos, retirando os momentos de reflexão, pausas, hesitações, e resultando em uma fala intermitente, o que, segundo ele, pode tornar o conteúdo mais interessante. Brown (2019) observa que há outras possibilidades de uso, como a retirada de falas que precisaram ser refeitas ou que se desviaram do tópico em andamento. Essa autora afirma que, muitas vezes, os youtubers utilizam essa técnica posicionando-se em diferentes lugares, criando um efeito de corte e de dinamicidade ainda mais intenso.

\section{A produção textual híbrida dos vlogs}

O vlog é um modo de produção textual que une vários recursos para produzir sentidos. Numa primeira observação, temos a impressão de estar diante de um texto falado autêntico, no entanto, ao investigarmos o seu modo de construção, veremos que se trata de um gênero que mescla elementos tanto da fala quanto da escrita. 
A tendência dos estudos da linguagem é ressaltar que essas modalidades apresentam muitas semelhanças. Marcuschi (2005) chega a dizer que é impossível identificar em um gênero textual algum traço linguístico formal que seja exclusivo de uma dessas modalidades. Segundo ele, todos os fenômenos podem aparecer em ambas, mas, evidentemente, cada uma apresenta estratégias organizacionais mais recorrentes.

Seguindo essa linha de raciocínio, Barros (2000) demonstra como, sob estratégias e procedimentos diferentes, os textos servem-se dessas duas modalidades para produzirem sentidos. Em sua análise, observa, por exemplo, que a questão temporal costuma ser apontada como um dos principais elementos de distinção entre fala e escrita, pois influenciaria nos graus de planejamento do texto.

As reflexões a respeito do planejamento levam em conta a natureza interacional da língua e as diferentes condições de produção da fala em relação à escrita (URBANO, 1998). Nesse sentido, considera-se que para a construção do texto são necessárias pelo menos duas atividades: uma cognitiva, para ativação e busca de ideias, e outra verbal, para a efetiva realização linguística.

A produção escrita preserva essas duas etapas, pois costuma apresentar uma distância de tempo entre o planejamento prévio do texto e a sua execução (Cf. URBANO, 1998). Este tipo de planejamento viabiliza a organização das ideias e a formalização do material linguístico.

Já os textos falados prototípicos são realizados localmente, de modo que as tomadas de decisão são feitas durante a interação. Assim, tanto a tarefa cognitiva quanto a verbal ocorrem de forma simultânea, não havendo, a princípio, como planejar o texto. Para Urbano (1998), na conversa espontânea, a etapa de planejamento prévio é 
improvável devido ao próprio caráter de espontaneidade. Assim, o planejamento será realizado durante a produção, com todas as consequências desse gesto.

A fim de explicitar os períodos de elaboração e produção do texto, Barros (2000) toma o gênero entrevista como exemplo. Para ela, este é um gênero que apresenta posições intermediárias em relação à fala/escrita a partir de três situações: entrevista falada (ao vivo), entrevista falada (editada), entrevista escrita. Vejamos:

\begin{abstract}
A questão da edição é mais complexa: se for uma entrevista ao vivo é menor o papel do editor e o tempo de edição é concomitante ao da entrevista; se não for ao vivo, é o editor quem, em última instância, produz o texto final, em um terceiro momento no tempo. É na edição que a entrevista passa de fala para a escrita, no caso do jornal ou das revistas, ou mantem-se como fala editada, no caso do rádio ou da televisão. A edição apara boa parte das marcas de reformulação, de repetição, de hesitação, etc, e altera as vezes o caráter entrecortado da fala" (BARROS, 2000, p. 62)
\end{abstract}

Nos exemplos citados pela autora, observamos, para além da entrevista falada, ao vivo, as possibilidades em que se pode haver edição do texto. No caso da entrevista escrita, o texto passaria por um processo de retextualização e editoração. Como lembra Marcuschi (2005), a retextualização envolve uma série de operações complexas para adequar o texto a novos propósitos comunicativos. Assim, ajusta-se a fala para a escrita, a escrita para a fala, ou ainda a fala para a fala e a escrita para a escrita.

Por fim, a fala editada diz respeito aos procedimentos de manipulação digital a que o áudio ou vídeo são submetidos, de modo que a fala mais espontânea é retextualizada (da fala para a fala) e adequada a um novo gênero. Para isso, são feitos basicamente cortes a fim de retirar os trechos indesejados e justapor som ou imagem. Além disso, podem ser usados outros efeitos de edição, como correção de cor, filtros, efeitos sonoros etc. Como afirma Barros (2000), esses procedimentos produzem o texto 
em um terceiro momento, também primordial: uma nova etapa de planejamento e edição. Somente após isso o texto é transmitido.

Observamos que é dentro dessa categoria que se encontram os vlogs, visto que há uma relação de concomitância entre o planejamento e verbalização, ao passo que há um terceiro momento em que há edição do material audiovisual. No entanto, apresentamos um elemento que extrapola o quadro da autora, que é o fato de que, ainda que possa haver apagamento de algumas marcas do processo de interlocução, há frequentemente outras que são evidenciadas visando provocar efeitos de sentido.

\section{0 fluxo formulativo}

Conforme aponta Jubran (2015), no texto falado, o fluxo da formulação pode ocorrer de modo contínuo, com estrutura linguística semelhante ao texto escrito prototípico, ou pode ainda se desenrolar com alguns obstáculos, ocasionando descontinuidades que alteram a organização sintática e canônica dos enunciados. Tais peculiaridades são decorrentes do fato de emergirem no momento da comunicação e de terem reduzido grau de planejamento prévio. Koch sistematiza essas características, que nos auxiliam a compreender a natureza emergencial dessa modalidade da língua:

1. é relativamente não-planejável de antemão, o que decorre de sua natureza altamente interacional: isto é, ela necessita ser localmente planejada, ou seja, planejada e replanejada a cada novo "lance" do jogo da linguagem;

2. O texto falado apresenta-se "em se fazendo", isto é, em sua própria gênese, tendendo, pois, a "pôr a nu" o próprio processo da sua construção (...)

3. O fluxo discursivo apresenta descontinuidades frequentes, determinadas por uma série de fatores de ordem cognitivo-interacional, as quais têm, portanto, justificativas pragmáticas relevantes (...)

4. O texto falado apresenta, pois, uma sintaxe característica, sem, contudo, deixar de ter como pano de fundo a sintaxe geral da língua; (...)

5. A escrita é o resultado de um processo, portanto estática, ao passo que a fala é processo, portanto, dinâmica. (KOCH, 2011, p. 79) 
São essas contingências da fala que fazem com que o texto seja monitorado constantemente, atendendo a pressões pragmáticas e interacionais. Assim, para Fávero, Andrade e Aquino (2015, p. 242), o locutor que produz seu texto não elabora apenas uma sequência verbal, mas realiza uma atividade interacional. Para eles, "formular é efetivar atividades que estruturam e organizam os enunciados de um texto". Os autores expandem essa ideia afirmando que o esforço que o locutor faz para produzir um enunciado se manifesta por traços deixados em seu discurso.

Nesse sentido, Jubran (1996) sustenta que o texto é a realização concreta da atividade interacional, de modo que os elementos pragmáticos se introjetam no material linguístico sendo possível perceber marcas da interação na superfície do texto. Desse modo, é comum encontrar na superfície textual fenômenos como repetições, hesitações, reinícios, correções, o que aparentemente causariam problemas na progressão do texto. (JUBRAN, 1996). Nos vlogs, em especial, notamos como essas atividades de formulação textual ganham destaque e como há uma a alta fragmentação da fala e o relevo para determinados segmentos fonológicos, lexicais, sintagmáticos.

Nessa perspectiva, o fato de partirmos do trabalho com vídeos demanda que consideremos a complexidade dos elementos que interferem na construção de sentido do texto. Assim, visto que nosso trabalho versa sobre a modalidade falada da língua, recortamos e transcrevemos trechos dos vlogs a partir das transcrições adotadas pelo Projeto Norma Urbana Culta (NURC), propostas por Castilho e Preti (1987).

Conscientes de que não existe transcrição perfeita, mas sim adequada aos objetivos definidos pelo pesquisador (MARCUSCHI, 2003), elaboramos um modelo de organização das transcrições baseado na segmentação do texto falado dos vlogs, conforme vemos a seguir: 
(1) gente... hoje a gente vai fazer um desafio...

que eu tô... realmente preocuPAda

passei a semana inteira preocupada com esse desafio...

porque:::

não é saudável fazer isso...

GENte...

mas eu nunca fiz isso...

então eu vou tentar...

gente peraí por causa que o sol tá tá nos atrapalhando

hoje eu vou fazer um desafio

MUlto

muito

muito

inusitado

que eu vou simplesmente

são 8 da matina

num sábado

acordei cedo e falei assim...

vamos acordar cedo

pra fazer o que?

maquiagem

só que eu não vou fazer uma maquiagem

e tipo assim já tirar... 
eu vou ficar VINte e quatro horas maquiada

vou dormir com make

e eu NUNca fiz isso nunca acho que fiquei tipo mais de

oito horas maquiada que já foi meu AUge

Procedendo dessa maneira, obtemos uma disposição gráfica dos dados que não é simplesmente linear, como tradicionalmente costumam ser apresentados nos estudos de língua falada. Porém, tal qual Marcuschi (1992), organizamos os dados já como uma préanálise que facilita a observação do fenômeno que propomos investigar - a fragmentação do fluxo formulativo.

Assim, esse modo de apresentação visual objetiva explicitar como a fragmentação é um traço frequente e regular dos vlogs. Conforme dissemos, isso ocorre em virtude do jump-cut, um recurso que se baseia no corte brusco das cenas e que provoca um efeito intencional de descontinuidade.

Nesse modelo, estabelecemos que cada corte nas cenas - e, consequentemente, no fluxo do texto falado - fosse transcrito sequencialmente, inaugurando uma nova linha. Isso já revela explicitamente uma das estratégias adotadas pelos editores dos vídeos para dinamizar o texto e também destacar alguns elementos, constituindo, muitas vezes, uma espécie de tópico sentencial.

Além disso, com esse exemplo, observamos que o uso dos jump-cuts ou a fragmentação do fluxo informacional não provoca problemas na coesão ou coerência nos textos, mas atribui um ritmo mais ágil e dinâmico. Frequentemente, essa dinamicidade costuma ser potencializada com mudanças no enquadramento das imagens, filtros, efeitos sonoros e outros efeitos de edição. 
Interessante notar também que, a princípio, o estudo dos textos falados era idealizado, apagando alguns elementos presentes em sua superfície. Com os vlogs, no entanto, ainda que seja possível ocultá-los na edição, observamos que são evidenciados, auxiliando na visualização de aspectos textuais-interativos como a interrupção, a repetição e a hesitação.

Embora essas estratégias se distanciem da fala prototípica, em que não há edições, ainda permanece um alto grau de espontaneidade, porém com um ritmo mais célere, dinâmico, e ajustado às necessidades do YouTube e da audiência.

\section{Considerações finais}

O modo de organização textual do vlog, em conjunção com uma diversidade de recursos multimodais, faz com que este seja considerado um gênero híbrido, mantendo características tanto da fala quanto da escrita.

Posto que os vlogs são compostos de materiais gravados, explicitamos que é comum os vídeos passarem por um momento de pós-produção no qual é dado um tratamento digital às imagens, a exemplo de inclusão de efeitos sonoros, inserção, justaposição ou exclusão de trechos. Esses fatores interferem diretamente na forma de apresentação do fluxo da fala, e, portanto, intervém no modo que esses textos produzem sentido, apresentando-os com maior expressividade.

Certamente algumas questões nos escapam, como por exemplo o fato de não termos acesso ao material bruto dos vídeos. Desse modo, provisoriamente, não temos respostas para perguntas como: os planos foram utilizados rigorosamente na sequência em que foram filmados? Quais trechos foram regravados? Quais foram suprimidos? Quais foram inseridos? Em quais há maior apoio ou influência de um texto escrito? 
A resposta a essas questões nos auxiliariam a compreender melhor o processo de elaboração dos vlogs, em virtude de o texto poder ser revisado após a produção. Veríamos, por exemplo, quais cenas ficaram de fora, e, a partir daí, ficariam mais evidentes as intenções comunicativas dos sujeitos quanto ao modo de apresentação da fala após a edição.

Por outro lado, a falta dessas informações não compromete a legitimidade do nosso trabalho, haja vista que a versão final do vídeo e o acabamento específico dado ao texto nos possibilitam compreender que há uma intenção comunicativa a fim de atingir determinados efeitos de sentido.

Nessa perspectiva, sabendo que os textos editados possibilitam que os locutores façam mais escolhas e reflitam sobre elas, acreditamos que as descontinuidades - seja com o uso dos jump-cuts e da consequente fragmentação do texto, seja com o destaque dado às atividades de formulação textual - são estratégias produtivas para despertar na audiência sensações de celeridade, espontaneidade, dinamicidade e comicidade.

Sob esse cenário, afirmamos então que, mesmo sendo altamente monitorado e construído artificialmente, é inegável que esse modo de utilizar a linguagem se constitui como um expediente relevante para as práticas comunicativas mediadas pela internet.

\section{Referências}

AMARO, F. Por um estudo dos vlogs: apontamentos iniciais e contribuições teóricas de Marshall McLuhan. Contemporânea. Rio de Janeiro: v. 9, 2011, p. 153-168.

AMARO, F. Uma proposta de classificação para os vlogs. COMUNICOLOGIA Brasília: v. 1, 2012, p. 79-108.

ASSIS, Robson. Edição de vídeo com jump cut. Disponível em https://site.ozi.com.br/edicao-video-jumpcut/ Acesso em 14 jun. 2019. 
BARROS, D. L. P. de. Entre a fala e a escrita: algumas reflexões sobre as posições intermediárias. In: Dino Preti. (Org.). Fala e escrita em questão. 1aed. São Paulo: Humanitas, 2000 p. 57-77.

BROWN, Liza. How To Use Jump Cuts in YourVlog. Disponível em https://filmora.wondershare.com/vlogger/how-to-use-jump-cuts-invlogging.html Acesso em 15 jun. 2019.

CASTILHO, A. T. de; PRETI, D. (orgs). A linguagem falada culta na cidade de São Paulo: materiais para seu estudo. São Paulo: T.A. Queiroz, Fapesp, 1987, v II.

COMOLLI, J. Algumas notas em torno da montagem. Devires: cinema e humanidades, Belo Horizonte: v.04, n.2, jul/dez. 2007, p.12-41.

COSTA, B. Videografias de si: Registros do novo ethos da contemporaneidade. Cadernos da Escola de Comunicação (Unibrasil), v. 5, 2007 .p. 3.

CRUZ, Dulce Márcia. Linguagem audiovisual: livro didático, 3. ed. rev. Palhoça: UnisulVirtual, 2010.

DIONISIO, A. P.; VASCONCELOS, L.; SOUZA, M. M. Multimodalidades e leituras:

funcionamento cognitivo, recursos semióticos, convenções visuais. 1. ed. Recife: Pipa Comunicação, 2014.

DONATO, D. S. Edição no Cinema e no Cotidiano: o sentido através do corte. 2009. Trabalho de Conclusão de Curso em Comunicação Social - Publicidade e Propaganda. Universidade de São Paulo: 2009.

EUFORICO. Como funciona o algoritmo do youtube. Disponível em https://www.euforico.net/2015/09/como-funciona-o-algoritmo-do-Youtube.html Acesso em 05 jan. 2020.

FÁVERO, L. L.; ANDRADE, M. L. C. V. O.; AQUINO. Oralidade e escrita: perspectiva para o ensino de língua materna. São Paulo: Cortez, 2000.

FÁVERO, L. L.; ANDRADE, M. L. C. V. O.; AQUINO, Z. G. O. Correção. In: JUBRAN, C. C. A. S.; $\mathrm{KOCH}$, I. G. V. (Orgs.). Gramática do português culto falado no Brasil. Campinas: Editora da Unicamp. vol. 1. Construção do texto falado, 2015, p. 241-256.

FERREIRA, L. M. S. O Jump-Cut no cinema de ficção português. Recurso artístico ou técnica narrativa? 2012. Dissertação. Mestrado em Som e Imagem. Escola das Artes da Universidade Católica Portuguesa, 2012.

GALEMBECK, P. de T.; Metodologia de Pesquisa em Português Falado. In: RODRIGUES, A. C. de S.; ALVES, I. M.; GOLDSTEIN, N. S. I Seminário de Filologia e língua Portuguesa. São Paulo: Humanitas/FFLCH, 1999. 
JUBRAN, C. C. A. S. Fundamentos Teóricos para a descrição Textual-Interativa do Texto Falado. Estudos Lingüísticos. São Paulo: v. XXV, 1996, p. 224-230.

KOCH, I. V. O texto e a construção dos sentidos. 10. ed. São Paulo: Contexto, 2011.

MARCUSCHI, J. A. A repetição na língua falada: formas e funções. Recife. Tese (Titular no concurso de lingüística) - Universidade Federal de Pernambuco, 1992.

MARCUSCHI, Luiz Antônio. Análise da Conversação. São Paulo: Ática, 2003.

MARCUSCHI, L. A. Da fala para a escrita: atividades de retextualização. 2. ed. São Paulo: Cortez, 2005.

MARCUSCHI, L.A. Produção textual, análise de gêneros e compreensão. São Paulo: Parábola Editorial, 2008.

URBANO, H. Variedades de planejamento no texto falado e no escrito. In: Dino Preti. (Org.). Estudos de língua falada: variações e confrontos. 1ed.São Paulo: Humanitas, v. 3, 1998, p. 115-140.

VAN LEEUWEN, T. Multimodality. In: SIMPSON, J. (Editor). The Routledge Handbook of Applied Linguistics. London and New York: Routledge: 2011, p. 668-682

YOUTUBE. PASSANDO 24H MAQUIADA! (O Teste mais ARRISCADO!) Disponível em https://www.youtube.com/watch?v=cJarrvggy40 Acesso em 12. Dez. 2019

Recebido em 27 de março de 2020.

Aceito em 28 de abril de 2020. 